\title{
Leitura e escrita no ensino superior: reconstruindo caminhos para as "literacias acadêmicas"
}

\author{
Reading and writing in higher education: \\ reconstructing pathways to "academic literacies" \\ Lectura y escritura en la enseñanza superior: \\ reconstruyendo caminos para las "literacidades académicas" \\ Dulce Helena Melão $\odot$ \\ Escola Superior de Educação de Viseu, Instituto Politécnico, Viseu, Portugal.
} $\diamond$

\begin{abstract}
RESUMO
O objetivo principal deste estudo é identificar e caracterizar as práticas de leitura e de escrita de estudantes de Comunicação Social e as suas possíveis repercussões em relação ao seu desenvolvimento profissional. Participaram 26 estudantes do $3^{\circ}$ ano (unidade curricular de Escrita Criativa) e os seus portfólios foram utilizados como instrumento de análise. Privilegiamos uma abordagem de natureza qualitativa, tendo como referencial metodológico o estudo de caso. Inferimos que: i) a maioria dos estudantes prefere ler em suporte impresso; ii) o seu perfil de leitor é multifacetado, destacando-se as categorias "leitor assíduo" e "leitor muito motivado"; iii) as suas práticas de escrita são diversificadas, sobressaindo os "textos pessoais" e as "notícias"; e iv) valorizam o contributo da escrita criativa para a sua futura profissão. Concluímos que tais práticas de leitura e de escrita exigem atenção redobrada em um contexto acadêmico, de modo a promover a sua diversidade, auxiliando os estudantes no seu futuro desempenho profissional.

Palavras-chave: Leitura. Escrita. Ensino superior. Literacias acadêmicas.
\end{abstract}

\begin{abstract}
This study aims to identify and characterize the reading and writing practices of Social Communication students, as well as to investigate the role played by such practices to foster their professional development. Participants were twenty-six students enrolled in a creative writing course $\left(3^{\text {rd }}\right.$ year). Portfolios were chosen as tools for collecting data. This study employed a qualitative single case study research approach. The results suggest that i) most students would prefer to read in print; ii) their reader profile is multifaceted, with emphasis on the categories of "frequent reader" and "highly motivated reader"; iii) their writing practices are diversified, with "personal texts" and "news" standing out; iv) they value creative writing to their future profession. We conclude that such reading and writing practices require increased attention in academic contexts, in order to encourage their diversity, fostering students' future professional performance.
\end{abstract}

Keywords: Reading. Writing. Higher education. Academic literacies.

\section{RESUMEN}

Este estudio tiene como objetivo identificar y caracterizar las prácticas de lectura y escritura de estudiantes de Comunicación Social, así como investigar cómo estas prácticas podrían contribuir a fomentar su desarrollo profesional. Los participantes fueron veintiséis estudiantes matriculados en un curso de escritura creativa ( $3 \mathrm{er}$ año). Los portafolios fueron las herramientas elegidas para la recolección de datos. Este estudio empleó un enfoque de investigación de estudio de caso único cualitativo. Los resultados sugieren que i) la mayoría de los estudiantes prefieren leer en forma impresa; ii) su perfil de lector es multifacético, con énfasis en las categorías de "lector frecuente" y "lector altamente motivado"; iii) sus prácticas de escritura están diversificadas, destacándose los "textos personales" y las "noticias"; iv) valoran la escritura creativa para su futura profesión. Concluimos que tales prácticas de lectura y escritura requieren una mayor atención en contextos académicos para fomentar su diversidad, fomentando el desempeño profesional futuro de los estudiantes.

Palabras clave: Lectura. Escritura. enseñanza superior. Literacidades académicas. 


\section{Introdução}

Participamos de processos comunicacionais de complexidade crescente que nos exigem um exercício de cidadania cada vez mais ativo nos quotidianos em que nos movemos, plasmados de diversidade e apelando à flexibilidade, em termos latos. A pluralidade e os respectivos desdobramentos das "literacias acadêmicas", na acepção que lhes atribuem Lea e Street (2006), refletem tal complexidade e repercutem-se, frequentemente, no tecido educativo, requerendo muita atenção (CARVALHO, 2015; DRENNAN, 2017). Assim, tendo como enquadramento teórico a literatura de especialidade respeitante à necessidade de reflexão permanente sobre tais literacias (síntese a ser realizada na primeira parte deste artigo), apresentamos aqui um estudo focado nas práticas de leitura e de escrita de estudantes do Ensino Superior (Curso de Comunicação Social, $3^{\mathrm{o}}$ ano), no âmbito da unidade curricular de Escrita Criativa. Entendemos que tal reflexão é profícua, dado que poucos estudos, em Portugal, incidem nessa temática, sendo relevante identificar e caracterizar tais práticas de modo a poder contribuir para uma reflexão mais aprofundada sobre as suas dimensões, delineando outros itinerários que possibilitem o crescimento dos estudantes enquanto futuros profissionais de Comunicação Social e, concomitantemente, favoreçam a criação de uma formação que possa fazer eco das suas expectativas e alimentem caminhos - de leitura, de escrita e dos mundos de que se (entre)tecem.

Após um breve enquadramento teórico, apresentamos o estudo realizado, a metodologia pela qual optamos e a análise dos resultados, em diálogo com a literatura especializada. Concluímos com algumas ilações retiradas dos percursos levados a cabo, apontando para outras vias de investigação que possibilitem a sua consolidação.

\section{Enquadramento teórico}

A evolução das práticas de leitura e de escrita na universidade é encarada como muito relevante por Carlino (2013), em seus estudos recentes. Embora centradas no contexto argentino, as considerações tecidas pela pesquisadora, no quadro extraordinariamente multifacetado do que hoje entendemos como leitura e como escrita (FULLER; SEDO, 2013; MARTOS NÚÑEZ; FERNÁNDEZ-FIGARES, 2012; MARTOS NÚÑEZ; GARCÍA, 2017), têm particular importância no contexto que nos ocupa. Quando encaradas como práticas sociais, a leitura e a escrita implicam, entre outros aspetos, de acordo com Carlino (2013), colaboração e cooperação entre professores de várias áreas, partilhando objetivos e valores comuns.
Ganha, hoje, particular ênfase a necessidade de participação ativa dos estudantes e dos professores para discutir e para repensar o que foi escrito e lido, de acordo com os objetivos traçados no âmbito do desenho da formação em que tais atividades se integrem. Nesse sentido, Carlino (2013) corrobora a necessidade de incluir todos os docentes universitários no labor da reconceptualização do ensino da leitura e da escrita no âmbito do que Carvalho (2013, p. 236) muito bem descreve enquanto "quadro alargado de práticas de literacia que envolvem a leitura e a escrita de gêneros textuais diversos em função dos contextos em que se inserem", indo ao encontro da sua multiplicidade, heterogeneidade e diversidade. Assim, se compreende que a indagação permanente no seio do debate sobre o ensino da leitura e da escrita no Ensino Superior implique no compromisso de docentes e de estudantes em práticas educativas que o encarem enquanto fio condutor ao longo da vida, nos antípodas de práticas fragmentadas que não se adequem aos atuais desafios comunicacionais da nossa sociedade. Acresce, como sublinham Alencar e Fleith (2010, p. 213), que “[...] também de fundamental importância é o fomento de uma cultura universitária que dê maior valor ao desenvolvimento e expressão do potencial criativo do estudante", fortalecendo-os.

Estudos recentes que contemplam práticas de escrita no ensino superior (por exemplo, CARDOSO; SEBASTIÃO; TEIXEIRA, 2018; MUNDÓ; BADİA, 2013; ROJAS; PUGA, 2017) têm possibilitado i) inferir a importância da realização de atividades contextualizadas que se caracterizem pela partilha de processos de escrita, potenciando interações profícuas entre os estudantes, bem como entre os estudantes e os professores; e ii) compreender as repercussões benéficas de que se pode revestir a definição de critérios de orientação de escrita do tipo/gênero textual pretendido.

Estudos cuja atenção principal incide nas representações da escrita e da leitura no Ensino Superior, ao nível da licenciatura (por exemplo, MELÃO; SILVA; BALULA, 2016; SOUSA; COSTA-PEREIRA, 2016), lançam também luz sobre as suas práticas literárias acadêmicas, enfatizando quer a sua diversidade, quer a necessidade de as conhecer de forma mais aprofundada, dada a sua complexidade, de modo a que possam ser encaradas enquanto matéria-prima de análise rigorosa e sustentada para o delinear da sua formação.

Outra linha de investigação que tem vindo a ser seguida aponta para a partilha de dimensões no âmbito do processo de escrita acadêmica e criativa, resguardando, todavia, a sua singularidade. Antoniou e Moriarty (2008) entendem que em tal partilha se inclui o desafio comum de validação e estímulo de modos de pensar (atravessados pela criatividade), que implicam rigor e excelência analítica, associados a competências de cariz técnico. 
Os autores sublinham a importância das repercussões das práticas de escrita criativa não só em trabalhos que possam vir a ser realizados pelos estudantes em contexto acadêmico (ensaios, relatórios etc.), como no âmbito do seu desenvolvimento pessoal e profissional futuro. A relevância do trabalho colaborativo no que respeita a tais práticas é igualmente encarada pelos autores como mais-valia para o fortalecimento de laços nos mundos que rodeiam os estudantes, a curto e a longo prazo. Yoo (2017) e Adsit (2017) corroboram, também, ser importante não ignorar os diferentes modos como a escrita criativa se pode plasmar, de forma vantajosa, na escrita acadêmica, dado a primeira implicar uma observação muito atenta, crítica e pormenorizada de tudo o que nos rodeia, constituindo uma necessária "aprendizagem do olhar".

Adicionalmente, o aumento da versatilidade dos escritores é também associado ao desenvolvimento do pensamento criativo, podendo se repercutir em práticas de escrita com fins diversificados e possibilitando dar voz aos nossos modos de estar no mundo, no âmbito dos quais também se implica a escrita acadêmica (ADSIT, 2017; YOO, 2017).

\section{Apresentação do estudo e metodologia}

Participaram deste estudo 26 estudantes (16 do sexo feminino e 10 do sexo masculino, identificados no texto de A1-A26) inscritos na unidade curricular de Escrita Criativa, integrada no 3 o ano do plano de estudos da licenciatura em Comunicação Social de uma instituição de Ensino Superior Portuguesa, no ano letivo de 2017/2018. A unidade curricular contempla $45 \mathrm{~h}$ presenciais e $63 \mathrm{~h}$ de trabalho autônomo do estudante.

No que diz respeito aos conteúdos programáticos da unidade curricular, importa referir que implicam em uma reflexão ampla sobre as dimensões plurais da criatividade, sendo dada particular atenção ao processo de escrita, enquanto se procura alimentar, com cuidado, o gosto pela leitura e o seu acolhimento. Associando as múltiplas dimensões da criatividade à escrita, promovemse, ainda, itinerários de descoberta de práticas de leitura e de escrita que possam contribuir para que, nos alicerces das representações dos estudantes, germinem espaços de reflexão sobre a sua condição de escritores. Como refere Mia Couto:

O escritor não é apenas aquele que escreve. É aquele que produz pensamento, aquele que é capaz de engravidar os outros de sentimento e de encantamento. Mais do que isso, o escritor desafia os fundamentos do próprio pensamento. Ele vai mais longe do que desafiar os limites do politicamente correcto. Ele subverte os próprios critérios que definem o que é correcto, ele questiona os limites da razão (COUTO, 2005, p. 63).
Dado o anteriormente exposto, este estudo teve como objetivo identificar e caracterizar as práticas de leitura e de escrita de estudantes, futuros profissionais da Comunicação Social que estavam frequentando o seu $1^{\mathrm{o}}$ ciclo de estudos, e suas possíveis repercussões no que concerne ao seu desenvolvimento profissional. A realização do estudo procura, igualmente, responder aos processos de indagação permanente sobre a nossa prática docente, integrando-se, a nível macro, nos objetivos traçados pela área disciplinar de Português da instituição de Ensino Superior na qual exercemos funções.

Foram colocadas as seguintes questões de investigação (QI):

- QI 1 - Quais as práticas de leitura e de escrita realizadas por estudantes, futuros profissionais da Comunicação Social, a frequentar um $1 \stackrel{0}{ }$ Ciclo de estudos de Bolonha?

- QI 2 - De que modos tais práticas de leitura e de escrita realizadas pelos estudantes se poderão repercutir no seu desenvolvimento profissional?

- QI 3 - Quais as principais dificuldades manifestadas por estes estudantes no que respeita ao processo de escrita?

Face aos objetivos delineados e às questões de investigação colocadas, optamos por realizar uma abordagem de natureza qualitativa, tendo como referencial metodológico o estudo de caso.

$\mathrm{O}$ instrumento de recolha de dados foi o portfólio, entregue no final da unidade curricular (em suporte impresso e em suporte digital), no entendimento de que, reunindo um conjunto de reflexões e de exercícios de escrita elaborados pelos estudantes, quer em contexto de sala de aula, quer no âmbito do seu trabalho autónomo, tal facultaria dados que possibilitassem contribuir para dar resposta às nossas indagações.

A técnica utilizada foi a análise de conteúdo, seguindo Bardin (2004), tendo sido geradas categorias a posteriori, após a análise detalhada dos enunciados. Tal procedimento foi realizado de forma a fazer emergir sentidos implícitos entrelaçados nos enunciados dos estudantes, procurando dar-lhes mais voz. Constituíram exceção, as categorias relativas às dificuldades apontadas no que tange à produção textual, no âmbito das dimensões respeitantes às etapas da planificação, da textualização e da revisão.

\section{Análise dos resultados e discussão}

No que diz respeito aos suportes de leitura preferidos pelos estudantes, destacou-se a categoria "Leitura em suporte impresso" (15 ocorrências, correspondendo a $60 \%$ ), tendo os participantes declarado ler, sobretudo, 
"Livros" (9 ocorrências, correspondendo a 36\%). Alguns mencionaram ainda que liam "Revistas" (3 ocorrências, correspondendo a 12\%), "Jornais desportivos' (2 ocorrências, correspondendo a $8 \%$ ) e "Semanários" (1 ocorrência, correspondendo a $4 \%$ ).

Relativamente à categoria "Leitura online", à qual foi atribuída menos relevância (registamos 8 ocorrências, correspondendo a $32 \%$ ), os estudantes afirmaram ler "Notícias", "Jornais generalistas" e "Blogues" (com um ligeiro predomínio das primeiras, em um total de 8 ocorrências, enquanto as duas subcategorias enunciadas tiveram 2 ocorrências cada uma - 8\%). Distinguimos, ainda, a "Leitura digital", assim apodada pelos estudantes, dizendo respeito ao lido no ecrã, sem implicar a navegação na internet. No âmbito dessa categoria foram referidos apenas "Artigos em PDF" e "Livros em PDF", perfazendo, cada um, 1 ocorrência (4\%).

O predomínio da leitura em suporte impresso está em linha com outros estudos que evidenciam hábitos de leitura de estudantes do "Ensino Superior em áreas de formação distintas (por exemplo, BALÇA; COSTA; PIRES; PAIS, 2009; BARON, 2015), embora, em alguns casos, se refira ser atribuída relevância semelhante a ambos os suportes (por exemplo, BORTOLANZA; BALÇA, 2013; YUBERO; LARRAÑAGA; PIRES, 2014).

No que respeita à "leitura online" o acesso privilegiado às notícias e a sua respetiva atualização é hodiernamente comum, compreendendo-se que os estudantes, dada a formação que frequentam, a privilegiem. A facilidade de acesso poderá, igualmente, ter sido um dos seus critérios de escolha. Importa, no entanto, ter em consideração, a par dos aspetos frisados, que ler online exige, por parte dos leitores, o domínio específico de um conjunto de estratégias de desenvolvimento de compreensão na leitura, cujo caráter multifacetado tem vindo a ser sublinhado na literatura de especialidade (COIRO, 2011; DOBLER; EAGLETON, 2015) - podendo tal ditar, em circunstâncias várias dependentes dos objetivos traçados pelos leitores, a opção pelo suporte impresso.

A parca importância concedida a "Artigos em PDF" e a "Livros em PDF" poderá explicar-se: i) pelo fato de preferirem o formato impresso; e ii) por eventuais dificuldades em selecionarem tais fontes, não as utilizando, com frequência, no âmbito de trabalhos acadêmicos que realizam.

No que respeita ao delinear do seu perfil de leitor, foram estabelecidas cinco categorias: i) "Leitor assíduo" (a mais destacada, com 10 ocorrências, correspondendo a $38 \%$ ); ii) "Leitor muito motivado"; (6 ocorrências, correspondendo a 23\%); iii) "Leitor desmotivado" (4 ocorrências, correspondendo a 15\%); iv) "Leitor seletivo"; e v) "Leitor ocasional" (ambos com 3 ocorrências, correspondendo a $12 \%)$.
Importa frisar que o critério que presidiu ao estabelecimento de categorias não disse respeito à quantidade de livros lidos, como, por vezes, sucede em estudos que contemplam os hábitos de leitura de estudantes do ensino superior, tendo, antes, emergido dos enunciados dos estudantes ou coincidido com a nomenclatura que utilizaram. A título ilustrativo como exemplo, trazemos dois depoimentos referentes às duas primeiras categorias mencionadas:

Sou uma leitora assídua, penso eu, leio com regularidade livros, às vezes leio revistas, mas tenho pena de ter pouco tempo para ler devido às aulas, o que também não me parece que vá mudar nos próximos tempos agora no fim do curso. (A14 ${ }^{1}$ )

Desde muito cedo estive rodeada pela literatura, pelos livros, pela imaginação com que os textos são escritos e pela criatividade e originalidade que fizeram com que aquelas obras fossem boas e se destacassem. Devido a todo esse contacto com a literatura e com os livros sou uma leitora muito motivada, sempre. (A172)

Enquanto no primeiro enunciado transparece o desalento da estudante pelas dificuldades associadas à gestão do trabalho acadêmico, no segundo enunciado as sílabas parecem iluminar-se pelo amor à leitura que porventura presidiu ao seu desenho. O contato precoce com os livros, associado a práticas de literacia familiar, tem sido apontado como um dos aspetos de relevo no que respeita ao incremento da motivação para a leitura (LEAL; GAMELAS; PEIXOTO; CADIMA, 2014; MATA, 2006; PINTO, 2010).

Relativamente às práticas de escrita dos estudantes, sobressaíram três dimensões, a nível macro: i) dimensão profissional; ii) dimensão pessoal; e iii) dimensão acadêmica. No âmbito da primeira dimensão, os estudantes declararam escrever "Textos jornalísticos" (13 ocorrências, correspondendo a 40\%), sendo concedido relevo às "notícias" (8 ocorrências, correspondendo a 25\%), seguidas das "reportagens" (3 ocorrências, correspondendo a 9\%) e das "crônicas" (2 ocorrências, correspondendo a $6 \%$ ).

Com similar importância, enquadrados na dimensão pessoal, foi dado relevo aos "Textos pessoais" (11 ocorrências, correspondendo a $35 \%$ ), sendo referidos os "diários" (5 ocorrências, correspondendo a 16\%), as "histórias" (4 ocorrências, correspondendo a 13\%) e os "poemas" ( 2 ocorrências, correspondendo a $6 \%$ ), sobressaindo ligeiramente os primeiros.

\footnotetext{
Depoimento de A14, recolhido através do portfólio entregue à pesquisadora no final da unidade curricular (ano letivo 2017/2018).

2 Depoimento de $\mathrm{A} 17$, recolhido através do portfólio entregue à pesquisadora no final da unidade curricular (ano letivo 2017/2018).
} 
No que respeita à dimensão acadêmica (a que menos se destacou), os estudantes atribuíram importância aos textos acadêmicos (8 ocorrências, correspondendo a $25 \%$ ), indicando, apenas os "relatórios" (2 ocorrências, correspondendo a 6\%) e as "reflexões" (6 ocorrências, correspondendo a 19\%), possivelmente por serem os que mais são solicitados nas unidades curriculares que frequentam.

No âmbito da categoria "Textos jornalísticos", um dos estudantes referiu, por exemplo: "Os textos que tenho mais tendência para escrever estão mais ligados à parte profissional, são textos jornalísticos precisamente derivado do meu interesse pela área do jornalismo e da imprensa escrita" (A2 ${ }^{3}$ ), evidenciando o seu particular gosto pela futura profissão que espera abraçar.

Relativamente à categoria "Textos pessoais", emergiram, de distintas formas, laivos de afeto que contribuem para o alicerçar da escrita enquanto processo de descoberta pessoal, com diferentes vertentes. Tal transparece nos dois enunciados que passamos a transcrever: "O que mais escrevo são textos pessoais, nomeadamente poemas porque me sinto melhor quando os escrevo mas também porque gosto e os sinto mais próximos" (A $\left.8^{4}\right)$; "Habitualmente os textos que escrevo são quase em formato de diário porque tal como o diário é pessoal as pequenas observações que transponho para o papel o são" (A125).

No que se refere às dificuldades apontadas pelos estudantes em relação à produção textual, dizendo respeito às suas componentes, distinguimos três categorias, correspondendo à planificação, à textualização e à revisão. Os estudantes declararam sentir mais dificuldades no que se refere à planificação, tendo emergido: i) "Dificuldades relativas ao estabelecimento de objetivos" ( 8 ocorrências, correspondendo a 36\%); e ii) "Desafios no âmbito da organização da informação" (5 ocorrências, correspondendo a $23 \%$ ).

No âmbito da primeira categoria apontada foi possível inferirmos que tais dificuldades eram preexistentes ao seu percurso acadêmico no Ensino Superior, não tendo sofrido alterações, como plasmado nos enunciados seguintes: "Escrever não é fácil, nunca foi. Continua a ser muito difícil estabelecer objetivos antes de escrever. Escrevo só da maneira que penso e sinto, como sempre fiz" (A5 $\left.5^{6}\right)$; "Para mim estabelecer objetivos antes de escrever foi sempre o caos e hoje continua a ser" (A217).

\footnotetext{
3 Depoimento de $\mathrm{A} 2$, recolhido através do portfólio entregue à pesquisadora no final da unidade curricular (ano letivo 2017/2018).

4 Depoimento de $\mathrm{A} 8$, recolhido através do portfólio entregue à pesquisadora no final da unidade curricular (ano letivo 2017/2018).

5 Depoimento de A12, recolhido através do portfólio entregue à pesquisadora no final da unidade curricular (ano letivo 2017/2018).

6 Depoimento de A5, recolhido através do portfólio entregue à pesquisadora no final da unidade curricular (ano letivo 2017/2018).

7 Depoimento de $\mathrm{A} 21$, recolhido através do portfólio entregue à pesquisadora no final da unidade curricular (ano letivo 2017/2018).
}

Quanto aos "Desafios no âmbito da organização da informação", os estudantes vincaram os esforços acrescidos inerentes à sistematização da informação enquanto aspecto que mais influenciaria a planificação do texto, indicando, por exemplo: "Quando começo a escrever até parece que está a ir bem só que depois penso: havendo tanta informação como organizo isto? Nunca tinha aprendido a planificar como era suposto e tenho tido dificuldades nos trabalhos acadêmicos" $\left(\mathrm{A} 16^{8}\right)$.

A "Articulação linguística (coerência e coesão)" e a "Clarificação/explicitação do conteúdo", com 2 ocorrências cada, correspondendo a 9\%, emergiram nos enunciados que associamos à textualização, sendo referidos por relatos como estes: "Continuo a escrever textos que muitas vezes, quando leio, não fazem sentido tal como eu queria, de modo a encadear as minhas ideias" (A $\left.3^{9}\right)$; "Sei que devo ser clara, sempre aprendi isso; continua a ser difícil porque nos trabalhos para as disciplinas temos de ler artigos que, às vezes não compreendemos bem, daí como explicar o conteúdo?" $\left(\mathrm{A} 10^{10}\right)$

No que se refere à revisão, foram destacadas "Dificuldades relativas à reescrita do texto" (3 ocorrências, correspondendo a 14\%) bem como à "Desvalorização da releitura do texto" (2 ocorrências, correspondendo a 9\%). No primeiro caso, foi possível descortinarmos que as dificuldades declaradas incutiam nos estudantes alguma frustração no contexto das práticas de escrita que realizavam, o que transparece nos enunciados seguintes: "Às vezes estou a ler o que escrevi e sei o que não está bem mas não consigo mudar (mesmo tentando várias vezes)" (A13 ${ }^{11}$ ); "Faço muitas tentativas para reescrever mas nunca fico satisfeita; depois já não sei se devia ter reescrito ou não. É um processo difícil" (A26 $\left.{ }^{12}\right)$.

Apesar da reconhecida atenção que tem sido conferida à natureza processual da escrita nas suas diversas componentes de planificação, de textualização e de revisão (BARBEIRO; PEREIRA, 2007; CARVALHO, 2015), os enunciados transcritos no parágrafo anterior revelam-nos que importa desenvolver um trabalho sustentado e rigoroso que possibilite aos estudantes do Ensino Superior enfrentar os desafios de escrita com que se deparam em contexto acadêmico, bem como no seu quotidiano.

\footnotetext{
8 Depoimento de $\mathrm{A} 16$, recolhido através do portfólio entregue à pesquisadora no final da unidade curricular (ano letivo 2017/2018).

9 Depoimento de $\mathrm{A} 3$, recolhido através do portfólio entregue à pesquisadora no final da unidade curricular (ano letivo 2017/2018).

${ }^{10}$ Depoimento de A10, recolhido através do portfólio entregue à pesquisadora no final da unidade curricular (ano letivo 2017/2018).

11 Depoimento de A13, recolhido através do portfólio entregue à pesquisadora no final da unidade curricular (ano letivo 2017/2018).

12 Depoimento de A26, recolhido através do portfólio entregue à pesquisadora no final da unidade curricular (ano letivo 2017/2018).
} 
No que se refere ao contributo da unidade curricular para o seu futuro desempenho profissional, destacou-se a categoria "Relação Leitura/Escrita" (31\%), seguindo-se às categorias "Relação escrita criativa/escrita com fins acadêmicos" (25\%) e "Partilha da produção escrita" $(17 \%)$. Relativamente à "Relação Leitura/Escrita", emergiram duas subcategorias: i) "Incremento da vontade de ler/escrever" (8 ocorrências, correspondendo a 19\%); e ii) "Relevância leitura/escrita para a futura profissão" (5 ocorrências, correspondendo a 12\%).

No que se refere à primeira subcategoria, os estudantes manifestaram o seu entusiasmo pelas práticas de leitura e de escrita, reconhecendo que a unidade curricular as teria estimulado para tal, o que emerge dos enunciados seguintes: "[...] despertou-me mais a vontade de ler e de escrever, e era isso mesmo que me faltava" $\left(\mathrm{A} 4{ }^{13}\right)$; "Tenho mais gosto pela leitura e pela escrita, o que se deve à forma como as aulas foram decorrendo, dando-nos ânimo para o fazer" (A18 $\left.{ }^{14}\right)$.

No respeitante à "Relevância leitura/escrita para a futura profissão", foi possível descortinarmos que os estudantes teriam realizado um processo de descoberta individual sobre o impacto de tais práticas no seu futuro próximo, sublinhando, por exemplo, as seguintes experiências: "Descobri que se lermos mais podemos dar outra roupagem à escrita e isso pode vir a ser um fator de maior influência na minha futura profissão porque hoje é tudo muito competitivo" (A115); "Tendencialmente separava muito uma coisa da outra; a verdade é que conhecer ou ler outros autores têm sido uma experiência boa que vai contribuir para escrever melhor na imprensa" $\left(\mathrm{A} 24^{16}\right)$. Nos dois enunciados transcritos emergem as repercussões positivas do incremento de práticas de leitura e de escrita na futura profissão dos estudantes, encarando-as na sua interdependência e conferindo-lhes estatuto de relevo.

A categoria "Relação escrita criativa/escrita com fins acadêmicos" desdobrou-se em duas subcategorias: "Importância da criatividade no processo de escrita" (4 ocorrências, correspondendo a 10\%) e "Contributo dos exercícios de escrita para a realização de trabalhos acadêmicos" (6 ocorrências, correspondendo a 5\%).

A primeira subcategoria possibilitou descortinar a relação intrínseca que os estudantes estabeleceram entre as práticas de escrita e a criatividade, concedendo um estatuto elevado a esta última, aspeto que transparece nos

\footnotetext{
13 Depoimento de A4, recolhido através do portfólio entregue à pesquisadora no final da unidade curricular (ano letivo 2017/2018).

14 Depoimento de $\mathrm{A} 18$, recolhido através do portfólio entregue à pesquisadora no final da unidade curricular (ano letivo 2017/2018).

15 Depoimento de $\mathrm{A} 11$, recolhido através do portfólio entregue à pesquisadora no final da unidade curricular (ano letivo 2017/2018).

16 Depoimento de $\mathrm{A} 24$, recolhido através do portfólio entregue à pesquisadora no final da unidade curricular (ano letivo 2017/2018).
}

enunciados seguintes: "Se nos preocupar-nos em escrever de forma criativa, isso pode melhorar a forma como escrevemos e daí podermos evoluir, o que não aconteceria sem criatividade" (A $\left.7{ }^{17}\right)$; "Quando escrevo procuro que a criatividade esteja presente porque torna a escrita diferente, mais agradável em qualquer circunstância, em muitos tipos de texto" (A1918). Embora reconheçamos que o conceito de criatividade é multifacetado, escapando (felizmente) a uma definição única, como apontado na literatura de especialidade (RUNCO, 2007; SAWYER, 2012; STERNBERG; KAUFMAN, 2018) entendemos ser relevante o destaque que os estudantes lhe concedem, face ao modo como tal representação poderá vir a repercutir-se a nível acadêmico e a nível profissional.

Relativamente à segunda subcategoria, um estudante sublinhou, por exemplo: "A nível do futuro de um profissional de Comunicação Social acho que esta unidade curricular representa um papel importante porque dá-nos a conhecer novas formas de criação de textos que podem ser fatores diferenciadores nos trabalhos acadêmicos" (A $\left.5^{19}\right)$. No enunciado transcrito está plasmado o reconhecimento do relevo das práticas de escrita, de cariz diversificado, levadas a cabo no âmbito da unidade curricular, bem como a sua possível influência para o sucesso da realização de trabalhos em contexto escolar. No que se refere à "Partilha da produção escrita", emergiram as subcategorias "Importância da partilha dos textos escritos individualmente" (3 ocorrências, correspondendo a 7\%) e "Promoção da cooperação (escrita em grupo)" (4 ocorrências, correspondendo a $10 \%$ ). O relevo concedido à partilha dos textos escritos individualmente transparece, com diferentes matizes, nos enunciados seguintes:

Embora no início tivesse algum receio, reconheço que foi importante partilhar os meus textos com os meus colegas. Foi assim que percebi que até escrevia bem e fiquei com outra noção sobre o que escrevo. Também foi bom ver o que os outros viam nos meus textos e eu não via, o que nunca tinha acontecido até agora $\left(\mathrm{A} 12^{20}\right)$.

Partilhar os textos que escrevi com os colegas teve benefícios para mim porque me ajudou a entender a forma como escrevia, ficando mais clara a perspectiva que quando alguém lê o que escrevemos interpreta-o de muitas formas que nós não pensamos (A2521).

\footnotetext{
17 Depoimento de A7, recolhido através do portfólio entregue à pesquisadora no final da unidade curricular (ano letivo 2017/2018).

${ }^{18}$ Depoimento de A19, recolhido através do portfólio entregue à pesquisadora no final da unidade curricular (ano letivo 2017/2018).

19 Depoimento de $\mathrm{A} 5$, recolhido através do portfólio entregue à pesquisadora no final da unidade curricular (ano letivo 2017/2018).

${ }^{20}$ Depoimento de $\mathrm{A} 12$, recolhido através do portfólio entregue à pesquisadora no final da unidade curricular (ano letivo 2017/2018).

${ }^{21}$ Depoimento de A25, recolhido através do portfólio entregue à pesquisadora no final da unidade curricular (ano letivo 2017/2018).
} 
A tomada de consciência sobre o processo de escrita levado a cabo, aliada à importância do olhar de Outros relativamente aos mundos que nela habitavam, transparece no primeiro enunciado, unido pelos elos da generosidade da partilha. No segundo enunciado, ecoam, também, os benefícios de tal generosidade, associada a uma reflexão mais apurada sobre a escrita e as suas repercussões nos leitores que dela cuidam.

No âmbito da segunda subcategoria, os estudantes declararam, por exemplo, o seguinte: "Escrever em grupo, para além da troca de ideias, foi um bom pretexto para conseguirmos cooperar mais, o que antes não acontecia" $\left(\mathrm{A} 5^{22}\right)$; "A escrita em grupo foi uma experiência diferente para mim mas tive oportunidade de dividir tarefas de escrita e de partilhar tudo, havendo cooperação entre todos" $\left(\mathrm{A} 10^{23}\right)$. O trabalho desenvolvido em cooperação, é, desde há muito, reconhecido na literatura de especialidade enquanto promotor de benefícios de interação gerados através da reavaliação de conhecimentos, do acolhimento de aprendizagens multifacetadas e de diferentes modos de estar (DAVIDSON; MAJOR, 2014; JOHNSON; JOHNSON; SMITH, 2014). Os enunciados dos estudantes corroboram a sua importância.

As "Competências transversais" foram também alvo de atenção por parte dos estudantes, tendo sido enfatizada a "Aquisição de ferramentas para o exercício da profissão" (2 ocorrências, correspondendo a 5\%) e a "Complementaridade escrita criativa/outras unidades curriculares" (5 ocorrências, correspondendo a 12\%).

No primeiro caso, os estudantes vincaram o seguinte: "Esta unidade curricular permitiu-me adquirir ferramentas para a minha profissão, quer se trate de escrita de textos mais simples, quer de outros que exigem criatividade e poderei usar noutros contextos" (A2324); "Adquiri ferramentas para exercer a função de jornalista de imprensa (o que eu quero) e para utilizar mais tarde, sempre que escrever" $\left(\mathrm{A} 15^{25}\right)$. No âmbito da segunda subcategoria, um estudante apontou, por exemplo, que a unidade curricular "[...] possibilitou uma maior facilidade no processo de escrita, não só nesta unidade curricular como em muitas outras e que se revelará, certamente, útil no nosso futuro profissional" (A1426). As afirmações dos estudantes vão ao encontro da reconhecida crescente necessidade de aquisição de competências transversais para obter sucesso, ao longo da vida, na sociedade em que

\footnotetext{
22 Depoimento de $\mathrm{A} 5$, recolhido através do portfólio entregue à pesquisadora no final da unidade curricular (ano letivo 2017/2018).

23 Depoimento de A10, recolhido através do portfólio entregue à pesquisadora no final da unidade curricular (ano letivo 2017/2018).

24 Depoimento de A23, recolhido através do portfólio entregue à pesquisadora no final da unidade curricular (ano letivo 2017/2018).

25 Depoimento de A15, recolhido através do portfólio entregue à pesquisadora no final da unidade curricular (ano letivo 2017/2018).

26 Depoimento de A14, recolhido através do portfólio entregue à pesquisadora no final da unidade curricular (ano letivo 2017/2018).
}

vivemos, plasmando-as nos universos laborais em que nos integramos (REDECKER et al., 2011; OECD, 2018).

A categoria "Conhecimento da língua" foi a que menos se destacou, tendo os estudantes concedido relevo à "Aquisição de vocabulário" e à "Articulação linguística (coerência e coesão)" (com duas ocorrências cada, correspondendo a 5\%). A menor ênfase colocada nessa categoria poderá dever-se à possibilidade de os estudantes entenderem ter alcançado um nível proficiente no que respeita ao conhecimento da língua, não valorizando tal aspeto no que concerne ao contributo da unidade curricular para o seu futuro desempenho profissional.

\section{Considerações finais}

As práticas de leitura e de escrita dos estudantes possibilitaram-nos, globalmente, compreender algumas das dimensões das "literacias acadêmicas" que exigem atenção redobrada, no Ensino Superior, sobretudo no que respeita à produção textual. De fato, as suas exigências crescentes apelam ao redesenho de uma formação que as possa acolher, contribuindo para o futuro desempenho profissional dos estudantes.

A maioria dos estudantes revelou gostar de ler, destacando-se os perfis "Leitor assíduo" e "Leitor muito motivado". No entanto, alguns declararam ler apenas de forma ocasional e outros manifestaram o seu desinteresse pela leitura. Tal permitiu-nos inferir que é necessário, em contexto escolar, continuar a realizar um trabalho sério e persistente que contribua para que a leitura seja entendida enquanto prazer.

Promover a diversidade de práticas de leitura e de escrita, em contextos multifacetados, poderá ser um dos itinerários a explorar com maior persistência no âmbito do plano de estudos de licenciatura dos estudantes, de forma transversal, em distintas unidades curriculares.

A realização de estudos longitudinais, que possibilitem aprofundar a caracterização das práticas de leitura e de escrita dos estudantes, poderá contribuir para reconstruir caminhos que os possam acolher, permitindo que progridam enquanto leitores e escritores que abram, por seu turno, percursos aos que com eles vão reconstruindo cidadanias.

\section{Referências}

ADSIT, Janelle. The writer and meta-knowledge about writing: threshold concepts in creative writing. New Writing, [s. l.], v. 14, n. 3, p. 304-315, Mar. 2017. https://doi.org/ 10.1080/14790726.2017.1299764

ALENCAR, Eunice Maria Lima Soriano; FLEITH, Denise de Souza. Criatividade na educação superior: fatores inibidores. Avaliação, Campinas, v. 15, n. 2, p.201-206, jul. 2010. https://doi.org/10.1590/S1414-40772010000200011 
ANTONIOU, Maria; MORIARTY, Jessica. What can academic writers learn from creative writers? Developing guidance and support for lecturers in higher education. Teaching in Higher Education, [s. l.], v. 13, n. 2, p. 157-167, Apr. 2008. https://doi.org/10.1080/13562510801923229

BALÇA, Ângela et al. Leitores em construção (?) Leitura(s) no ensino superior em Portugal: alguns indicadores. In: MARTOS, Eloy; RÖSING, Tania M. K. (coord.) Prácticas de lectura y escritura. Passo Fundo: Universidade de Passo Fundo, 2009. p. 237-258.

BARBEIRO, Luís Filipe; PEREIRA, Luísa Álvares. O ensino da escrita: a dimensão textual. Lisboa: Direção-Geral de Inovação e de Desenvolvimento Curricular, 2007.

BARDIN, Laurence. Análise de conteúdo. 3. ed. Lisboa: Edições 70, 2004.

BARON, Naomi. The fate of reading in a digital world. Oxford: Oxford University Press, 2015.

BORTOLANZA, Ana Maria Esteves; BALÇA, Ângela. Perfil leitor de universitários ingressantes em um curso de formação de professores. In: CHALETA, M. L. et al. (coord.). Actas da II international conference learning and teaching in higher education and learning orchestration in higher education. Évora: Universidade de Évora, 2013. p. 279-296.

CARDOSO, Adriana, SEBASTIÃO; Isabel; TEIXEIRA, Carla. Escrita colaborativa no ensino superior: análise exploratória da interação entre pares no quadro do interacionismo sociodiscursivo. In: BROCADO, M. Teresa; CORREIA, C. Nunes (org.). Cadernos WGT: (novos) balanços e perspetivas. Lisboa: FCSH, 2018. p. 19-26.

CARLINO, Paula. Alfabetización académica diez años después. Revista Mexicana de Investigación Educativa, [s. l.], v. 17, n. 57, p. 355-381, abr./jun. 2013.

CARVALHO, José António Brandão. Aula de língua e literacia académica: rupturas e interseções. Linguagem \& Ensino, Pelotas, v. 18, n. 1, p. 79-97, jan./jun. 2015.

CARVALHO, José António Brandão. A transição para o ensino superior: novos contextos, novas práticas de literacia. In: PEREIRA, L. Álvares; CARDOSO, Inês (coord.). Reflexão sobre a escrita: o ensino de diferentes géneros de textos. Aveiro: Universidade de Aveiro, 2013. p.225-239.

COIRO, Julie. Predicting reading comprehension on the Internet: contributions of offline reading skills, online reading skills, and prior knowledge. Journal of Literacy Research, [s. l.], v. 43, n. 4, p. 352-392, Dez. 2011. https://doi. org/10.1177/1086296X11421979

COUTO, Mia. Pensatempos: textos de opinião. Lisboa: Editorial Caminho, 2005.

DAVIDSON, Neil; MAJOR, Claire Howell. Boundary crossings: cooperative learning, collaborative learning, and problem-based learning. Journal on Excellence in College Teaching, [s. l.], v. 25, n. 3/4, p. 7-55, Mar. 2014.
DOBLER, Elizabeth.; EAGLETON, Maya B. Reading the web. 2. ed. New York: Guildford Press, 2015.

DRENNAN, Laura. Traversing the spaces of higher education through writing. Reading \& Writing, [s. l.], Cape Town, v. 8, n. 1, p. 1-8, Apr. 2017. https://doi.org/10.4102/rw.v8i1.126

FULLER, Danielle; SEDO, DeNel Rehberg. Reading beyond the book: the social practices of contemporary literary culture. New York: Routledge, 2013. https://doi.org/ $10.4324 / 9780203067741$

JOHNSON; David W.; JOHNSON, Roger T.; SMITH, Karl A. Cooperative learning: Improving university instruction by basing practice on validated theory. Journal on Excellence in University Teaching, v. 25, n. 3/4, p. 85-118, mar. 2014.

LEA, Mary R.; STUART, Brian. The academic literacies model: theory and applications. Theory Into Practice, [s. l.], v. 45 , n. 4, p. 368-377, June 2006. https://doi.org/10.1207/ s15430421 tip4504_11

LEAL, Teresa et al. Linguagem e literacia emergente: propostas de intervenção em jardim de infância. In: VIANA, F. Leopoldina; RIBEIRO, Iolanda; BAPTISTA, Adriana (coord.). Ler para ser: os caminhos antes, durante e... depois de aprender a ler. Coimbra: Almedina, 2014. p. 175-205.

MARTOS NUÑEZ, Eloy; CAMPOS FERNÁNDEZFIGARES, Mar. La lectura y la escritura en el seculo XXI: Cultura letrada y modernidad. Álabe, Almería, n. 5, p. 1-12, jun. 2012.

MARTOS NUÑEZ, Eloy; GARCÍA, Alberto Eloy Martos. La lectura universitaria y los mitos de la alfabetización. In: LEYVA, Elsa M. Ramírez (coord.). La enseñanza de la lectura en la universidad. México: UNAM, 2017. p.3-28. https://doi.org/10.15645/Alabe.2012.5.13

MATA, Lourdes. Literacia familiar: ambiente e descoberta da linguagem escrita. Porto: Porto, 2006.

MELÃO, Dulce; SILVA, Ana I.; BALULA, João P. Práticas de leitura e de escrita de futuros profissionais da educação social: dos fios que se tecem as suas representações. In: GOMES, Cristina A. et al. (org.). Atas do XIII Congresso SPCE: fronteiras, diálogos e transições na educação. Viseu: Escola Superior de Educação de Viseu, 2016. p. 292-301.

MUNDÓ, Ana Camps; BADÍA, Monserrat Castelló. La escritura académica en la universidad. Revista de Docencia Universitaria, [s. l.], v. 11, n. 1, p. 17-36, 2013. https://doi. org/10.4995/redu.2013.5590

OECD. The future of education and skills: education 2030. Paris: OECD, 2018.

PINTO, Maria da Graça Lisboa Castro. As bases da leitura: entre a "ciência" da literacia precoce e a "ciência" do jogo. Letras de Hoje, Porto Alegre, v. 45, n. 3, p. 26-34, jul./set. 2010. 
REDECKER, C. et al. The future of learning: preparing for change. Luxembourg: Publications Office of the European Union, 2011.

ROJAS, Laura Teresa Rayas; PUGA, Ana María Mendez. Los estudiantes universitarios ante la escritura del ensayo académico: dificultades y posibilidades. Innovación Educativa, v. 17, n. 75, p. 123-147, sept./dic. 2017.

RUNCO, Mark A. Creativity: theories and themes: research, development and practice. London: Academic Press, 2007.

SAWYER, Keith. Explaining creativity: the science of human innovation. Oxford: Oxford University Press, 2012.

STERNBERG, Robert; KAUFMAN, James C. (org.). The nature of human creativity. Cambridge: Cambridge University Press, 2018.

SOUSA, Otília Costa; COSTA-PEREIRA, Teresa. Escrita, leitura e aprendizagem: um estudo exploratório no ensino superior. EXEDRA, [s. l.], n. temático, p. 213-233, dez. 2016.

YOO, Joanne. Writing out on a limb: integrating the creative and academic writing identity. New Writing, v. 14, n. 3, p. 444-454, may 2017. https://doi.org/10.1080/14790726. 2017.1317274

YUBERO, Santiago; LARRAÑAGA, Eloy; PIRES, Natividade. Estudo sobre os hábitos de leitura dos estudantes portugueses do ensino superior. Castelo Branco: Edições IPCB, 2014

Recebido em: 13/11/2018

Aprovado em: 22/5/2019.

Publicado em: 5/11/2019.

Autora:

Dulce Helena Melão

Doutora em Educação pela Universidade de Aveiro (Portugal).

Escola Superior de Educação de Viseu (ESEV), Instituto Politécnico,

Viseu, Portugal.

Orcid: https://orcid.org/0000-0002-1608-1074

E-mail: dulcemelao@esev.ipv.pt

Endereço: Rua Dr. Maximiano Aragão, 41

3500-155, Viseu, Portugal 